\title{
Membangun Etos dan Kearifan Lokal melalui Foklor: Studi Kasus Foklor di Tembalang Semarang
}

\author{
Elsa Fitrianita, Fanny Widyasari, Widiastri Indah Pratiwi \\ Program Studi Antropologi Sosial, Fakultas Ilmu Budaya, \\ Universitas Diponegoro Semarang
}

\begin{abstract}
This study aims to determine the relationship between folklore and work ethos in Tembalang District. In the cultural inheritance of society internalize through oral culture or commonly referred to as folklore. The method of research is done by primary data collection (interview) and secondary (literature study). Primary data collection through taking five sample villages in Tembalang District. The informants we obtained in folklore research came from core informants and ordinary informants totaling 8 people. The analysis used qualitative techniques by describing the data obtained. The results showed that the Tembalang District community had folklore divided into three types, namely oral literature (oral folklore), performance folk arts (performing arts), and folk custom social (people's social habits). Folklore that develops into a local tradition with an understanding of local wisdom will preach beliefs in a spirit of togetherness and can make a community identity so that it is also realized in the identity of individuals who can create ethos in society.
\end{abstract}

Key Words: Folklore, Local Wiwsdom,, Ethos

\section{Pendahuluan}

Kebudayaan atau yang disebut peradaban, mengandung pengertian yang luas, meliputi pemahaman perasaan suatu bangsa kompleks, meliputi pengetahuan, kepercayaan, seni, moral, hukum, adat-istiadat (kebiasaan), dan pembawaan lainnya yang diperoleh dari anggota masyarakat (Taylor, 1897).

Dalam kehidupan masyarakat khususnya masyarakat pedesaan pastinya memiliki suatu kebudayaan apalagi masyarakat Indonesia yang dikenal sebagai masyarakat yang multikultural. Masyarakat tentunya mengalami perkembangan dari waktu ke waktu, dari yang tradisional menjadi masyarakat yang modern. Masyarakat tradisional dikenal dengan kebudayaannya yang masih kental, kebudayaan ini mereka pelajari dari alam, pengalaman kehidupan sosial mereka serta komunikasi simbolik seperti yang dituturkan oleh Parsudi Suparlan. Pengetahuan-pengetahuan tersebut yang mereka dapatkan lalu di teruskan ke generasi penerus mereka dengan cara yang mudah di pahami oleh masyarakat tradisional. Walaupun sederhana tetapi memiliki banyak makna, hal inilah yang dijelaskan dalam interaksionisme simbolik.

Dalam pewarisan kebudayaan masyarakat menginternalisasi budaya melalui kebudayaan lisan atau biasa disebut dengan folklor. Foklor merupakansebagian kebudayaan suatu kolektif, yang tersebar dan diwariskan turun-temurun, diantara kolektif macam apa saja, secara tradisional dalam versi yang berbeda, baik dalam bentuk lisan maupun contoh 
yang disertai dengan gerak isyarat atau alat pembantu pengingat. Dewasa ini folklor kurang diperhatikan, hal ini terbukti dengan banyaknya ketidaktahuan warga, khususnya warga Kecamatan Tembalang Kota Semarang, ketika diminta keterangan untuk menceritakan salah satu asal-usul daerah yang ada di Kecamatan Tembalang. Pengetahuan tentang folklor hanya diketahui oleh sebagian kecil masyarakat yang sudah berusia lanjut atau warga yang sudah lama menetap di Kecamatan Tembalang dan sebagian instansi pemerintah desa.

Pemajuan tentang kebudayaan sudah menjadi perhatian pemerintah, Undang-Undang Pemajuan Kebudayaan masuk dalam pasal 32 ayat 1 dalam Bab I yang berisi tentang pemajuan (memuat tentang penjelasan umum, perlindungan (inventarisasi, pengamanan, pemeliharaan, penyelamatan, dan publikasi), pengembangan, pemanfaatan, dan pembinaan dan Bab II tentang Hak dan Kewajiban (setiap orang dalam upaya memajukan Kebudayaan). Namun faktanya Undang-Undang ini belum terlaksana sepenuhnya karena kurangnya kesadaran masyarakat akan pentingnya merawat dan melestarikan pengetahuan tentang Kebudayaan.

Artikel ini bertujuan untuk membahas tipe oral literature (folklor lisan), Performaing folk arts (seni pertunjukan ), dan social folk custom (kebiasaan sosial rakyat) seperti cerita rakyat, mitos, tradisi, dan kesenian dari Kecamatan Tembalang sehingga dapat dijadikan sebagai alat untuk menyadarkan masyarakat akan pentingnya pengetahuan tentang Kebudayaan untuk membangun etos kerja dalam masyarakat.

Riset ini mengambil fokus pada kajian mengenai folklor yang hidup di suatu satuan sosial tertentu kaitannya dengan penguatan etos. Dalam hal ini, foklor adalah pengindonesian dari kata folklore. Folk artinya sama dengan kolektif. Menurut Dundes folk adalah sekelompok orang-orang yang memiliki ciri-ciri pengenal fisik, sosial dan kebudayaan, sehingga dapat dibedakan dari kelompok-kelompok lainnya. Ciri-ciri pengenal itu antara lain, warna kulit, bentuk rambut, mata pencaharian, bahasa, pendidikan dan agama yang sama. Namun yang penting adalah mereka telah mempunyai tradisi, yaitu kebudayaan yang telah di wariskan turun-menurun sedikitnya oleh dua generasi untuk dapat diakui sebagai tradisi milik bersama, dan mereka sadar akan identitas kelompok mereka sendiri. Sedangkan yang dimaksud dengan lore adalah tradisi folk, yaitu sebagian kebudayaan, yang diwariskan secara turun menurun secara lisan atau melalui gerak isyarat atau alat pembantu pengingat. Jadi secara keseluruhan arti folklor adalah sebagian kebudayaan suatu kolektif, yang tersebar dan diwariskan tururn-temurun, dalam kolektif macam apa saja, secara tradisional dalam versi yang berbeda baik dari bentuk lisan dan maupun contoh yang disertai gerak isyarat atau alat pembantu pengingat.

Objek penelitian folklor di Indonesia adalah semua folklor yang ada di Indonesia, baik yang di pusat maupun di daerah, yang kota maupun yang desa, baik kraton maupun kampung, baik pribumi maupun keturunan asing (peranakan), baik warga negara maupun asing, asalkan mereka sadar akan identitas kelompok, dan mengembangkan kebudayaannya di Indonesia.

Ciri-ciri folklor menurut James, 1991 adalah: (1) Penyebaran biasanya dilakukan secara lisan, dari mulut kemulut dari generasi ke generasi berikutnya. (2) Bersifat tradisional, disebarkan dalam jangka waktu yang lama. Paling sedikit 2 generasi. (3) Bersifat anonym, atau yang artinya nama sang pencipta folklor tidak diketahui lagi. (3) Folklor berfungsi sebagai alat pendidik dan protes sosial. (4) Folklor bersifat pralogis, yaitu mempunyai logika sendiri yang berbeda dengan logika pada umumnya. (5) Folklor adalah milik bersama. (6) Folklor terlihat polos dan lugu, sehingga terkesan kasar dan spontan, itu karena agar mudah di pahami dan diingat.

Dorson (1972, dalam Endraswara) mengklasifikasikan folklore sebagai berikut: (1) Oral literature, kadang-kadang disebut juga sebagai seni verbal atau sastra ekspresif. Sastra lisan adalah bagian dari folklor yang menjadi ruh folklor. Sastra lisan pula yang menguatkan 
folklor hingga lekat dihati pendukungnya. (2) Budaya materi, yaitu folklor yang kontras dengan sastra lisan. Budaya folklor adalah kehidupan fisik. Folklor semacam ini terkait dengan karya, seperti pakaian, design, candi, dan sebagainya. (3) Social folk custom, artinya kebiasaan sosial rakyat. Kebiasaan ini menyangkut tradisi rakyat. Hal-hal yang berhubungan dengan rites de passage, seperti kelahiran, inisiasi, ekmatin, dan ritual lainnya adalah folklor. (5)Performaing folk arts artinya seni pertunjukan rakyat, seperti jatilan, ketoprak, srandul, dan sebagainya.

Adapun konsep lain yang dikaji adalah etos. Etos dalam hal ini adalah istilah yang berasal dari bahasa Yunani ethikos, yang berarti moral atau menunjukkan karakter moral.Dalam bahasa Yunani kuno dan modern, etos berarti keberadaan diri, jiwa, dan pikiran yang membentuk seseorang.Dalam Webster's NewWord Dictionary, 3rd College Edition dikemukakan bahwa etos berarti kecenderungan atau karakter; sikap, kebiasaan, keyakinan yang berbeda dari individu atau kelompok. Etos berhubungan juga dengan etika, seperti rajin, bekerja keras, berdisiplin tinggi, menahan diri, ulet, dan tekun. Dalam Kamus Besar Bahasa Indonesia (Depdiknas, 2003:309-310) disebutkan bahwa etos berarti pandangan hidup yang khas dari suatu golongan sosial (dalam Harun. 2015: 76).

\section{Metode}

Penelitian ini dilakukan di Kecamatan Tembalang Kota Semarang. Penelitian Folklor ini mengambil 5 sempel Desa yang ada di Kecamatan Tembalang Semarang, yaitu Desa Tembalang, Desa Meteseh, Desa Kramas, Desa Sendangmulyo, dan Desa Bulusan. Penelitian dilakukan dari bulan April sampai Mei 2018. Data yang diambil dalam penelitian tipe folklor oral literature (folklor lisan), performaing folk arts (seni pertunjukan), dan social folk custom (kebiasaan sosial rakyat) untuk mengetahui mengenai makna simbolik dibalik suatu cerita rakyat, mitos, tradisi dan kesenian.

Penentuan informan menggunakan dua pendekatan yaitu informan kunci dan informan biasa. Informan kunci merupakan informan yang memegang peranan penting yang akan memberi tahu seputar folklor, biasanya kita dapati dalam instasi pemerintah, dan tokoh masyarakat. Informan biasa menjadi informan pendukung pengumpulan data folklor biasanya sebagai penikmat dan pelaku folklor. Informan yang diperoleh di lima desa di Kecamatan Tembalang delapan orang tokoh yang berasal dari instansi pemerintah, tokoh masyarakat, dan informan biasa.

Pengumpulan data berupa data primer dan data skunder. Data primer adalah data yang diperoleh secara langsung melalui proses wawancara mendalam kepada informan seputar kejadian historis folklor mengenai tradisi lisan dan kebiasaan masyarakat yang menyangkut cerita rakyat, mitos dan tradisi yang ada pada setiap desa. Data sekunder adalah data pendukung yang bersumber dari studi pustaka maupun referensi yang didapat dari instansi pemerintah desa ataupun warga masyarakat.

Ada beberapa jenis wawancara yang dapat digunakan menurut Vredenbregt (1984: 92) berdasarkan strukturnya, yaitu wawancara terstruktur dan tidak terstruktur. Perbedaan tipe ini akan membengaruhi jawaban dari informan sehingga dapat dibuat tabel seperti berikut:

\begin{tabular}{|l|l|l|}
\hline \multirow{2}{*}{ Stimuli (Pertanyaan) } & \multicolumn{2}{|c|}{ Responses (Jawaban) } \\
\cline { 2 - 3 } & Lisan (oral) & Tertulis (Written) \\
\hline Tidak berstruktur & Terbuka(Open ended) & Terbuka \\
\hline Berstruktur & Berstruktur & Berstruktur \\
\hline
\end{tabular}


Penelitian ini fokus pada jenis wawancara mendalam dan menggabungkan diantara kedua teknik tersebut untuk menghasilkan jawaban secara lisan sesuai dengan teknik wawancara kualitatif.

Metode analisis data yang dipergunakan dalam penelitian ini ialah analisis kualitatif. Metode penelitian kualitatif adalah metode penelitian yang berlandaskan pada filsafat positivisme, digunakan untuk penelitian yang berlandaskan pada filsafat postpositivisme, digunakan untuk meneliti pada kondisi objek alamiah, (sebagai lawannya adalah eksperimen) dimana peneliti adalah sebagai instrument kunci, pengambilan sampel sumber data dilakukan secara purposive dan snowball, teknik pengumpulan dangan triangulasi (gabungan), analisis data bersifat induktif/kualitatif, dan hasil penelitian kualitatif lebih menekankan makna dari pada generalisasi (Sugiyono, dalam Hayati:347). Yanagita dkk mengungkapkan cara dalam menganalisis folklor 1). Pemilihan, penanganan dan pencatatan data-data penting, 2).Pengendalian dan pemilihan data, 3).Pengklasifikasian data ke dalam folklor material, folklor lisan dan folklore adat istiadat kolektif masyarakat (Endraswara, 2009).

\section{Hasil dan Pembahasan}

Masyarakat Kecamatan Tembalang merupakan masyarakat yang masih kental dengan cerita lisan, tradisikesenian dan kearifan lokalnya. Hampir di setiap desa yang ada di Kecamatan Tembalang mempunyai unsur folklor yang sama, namun ada yang membedakan antara desa satu dengan lainnya, yakni dalam asal usul cerita daeranya yang mempengaruhi semangat pada etos kerja.

\subsection{Foklor di Wilayah Kecamatan Tembalang}

\subsubsection{Foklor di Desa Bulusan}

Desa Bulusan, Kecamatan Tembalang dengan jumlah penduduknya sebanyak 5636 yang terdiri dari laki-laki sebanyak 2865 jiwa dan perempuan 2771 jiwa. Desa Bulusan merupakan penggabungan antara dua desa yaitu desa Bulusan dan desa Ngembak yang ada di Kec, Tembalang. Desa Bulusan menurut sejarahnya berasal dari kata Bulu dan Alas. Bulu merupakan nama sebuah pohon yang hanya ada di desa Bulusan. Pohon bulu ada di jaman penjajahan. Pada saat ini pohon Bulu sangat bermanfaat bagi pribumi dalam semangat melawan musuh, hal ini dikarenakan pohon Bulu digunakan sebagai pelindung dari serangan penjajah sedangkan alas dalam bahasa Indonesia berarti hutan, pada zaman dahulu desa bulusan merupakan suatu alas yang banyak pohon-pohon besar. Sedangkan desa Ngembak merupakan desa yang berada di sebrang jalan desa bulusan. Desa Ngembakberasal dari banyaknya tanah yang ditambak karena dulunya Desa Ngembak sering mendapat kirimah air dari Tlogosari, tambak itu juga digunakan sebagai pembatas antar desa.

Daerah bulusan yang terdiri dari bagian alas/ hutan terlihat dari jalan yang bernama sigar bencah. Hamper di seluruh kiri kanan jalannya merupakan sebuah jurang dengan banya pepohonan. Mitosnya pada zaman dahulu ketika akan di buat suatu jalan penghubung menuju desa Meteseh, harus diadakan suatu ritual memohon izin kepada penunggunya. Diceritakan bahwa penunggu daerah sigar bencah dahulu adalah seorang pangeran dari kerajaan demak yang menyamarkan namanya enjadi Ngotruno yang mendatangi daerah bulusan unuk menupas ajaran sesat yang dibawah oleh danyang/ penunggu pertama wilayah bulusan yang bernama Ki Samber Nyowo, namun pada saat sampai di daerah sigar bencah.pangeran itu kemudian di hadang oleh orang penganut ajaran sesat dan kemudian di bencah-bencah atau di mutilasi, sehingga nama jalan itu kini di kenal sebagai jalan sigar bencah. 


\subsubsection{Foklor di Desa Tembalang}

Desa Tembalang, Kecamatan Tembalang berada di ketinggian 200 mdpl, dengan suhu maksmimum $32^{\circ}$. Tembalang berasal dari kata tambal dan ilang yang artinya di tambal dan hilang. Ada dua versi mengenai asal usul Desa Tembalang, yang pertama dahulu di Tembalang ada sebuah mata air besar yang airnya bocor dan menyebabkan air kemana-mana lalu jika ada orang yang sedang bercocok tanam, mereka harus duduk bersila agar tidak tenggelam, mereka akhirnya jenuh dengan mata air yang selalu mengalir terus padahal sudah di tambal namun selalu hilang. Hingga akhirnya datang Ki Ageng Pandang Arang yang mengusulkan untuk melakukan selamatan dengan menyembelih kerbau kemudian kepala kerbau itu untuk menambal mata air yabg bocor itu, dan dagingnya dibagikan kepada warga sebagai sedekah. Kemudian setelah ditutup mata air itu terbagi menjadi sembialn sumber mata air.

Dan versi ke-2 mengatakan bahwa dulu ada mata air yang berjumlah sembilan, karena khawatir akan menenggelamkan Tembalang maka mata air itu di tutup memakai batu besar namun batunya tidak kuat menahan aliran air tersebut sehingga batunya hilang, lalu datanglah Ki Ageng Pandan Arang, beliu bertanya pada warga apa yang sedang mereka lakukan, lalu warga bercerita bahwa mereka ingin menutup mata air tersebut karena takut menenggelamkan Tembalang, kemudian Ki Ageng Pandan Arang mengajak warga untuk sholat dua rakaat, setelah solat selesai Ki Ageng Pandan Arang berkata bahwa jika aku sudah pergi dari tempat ini maka hanya akan tersisa satu sumber mata air saja, dan benar saja setelah beliau pergi mata air itu hanya tersisa satu.

\subsubsection{Foklor Desa Kramas}

Desa Kramas, Kecamatan Tembalang berada pada 280 mdpl dengan suhu minimum $38^{\circ}$ dan maksimum $30^{\circ}$.Kramas merupakan sebuah Desa yang dulunya ikut dalam kecamatan Banyumanik. Kramas diambil dari salah satu kegiatan yang dilakukan saat mandi yaitu kramas. Konon ada orang yang lelah setelah bekerja lalu ingin mandi untuk menyegarkan badannya kemudian ia jalan-jalan pada sore hari ke sebuah sendhang yang di pinggir sendhang Semak, lalu dia mandi dan kramas setelah itu dia merasa segar kembali. Kemudian dia berkata jika suatu saat ada desa yang akan di bangun nantinya akan di namai Kramas.

Mitos yang berkembang di desa Kramas ialah, di depan Kelurahan Kramas ada pohon beringin tua dan terdapat batu besar yang ditunggu oleh Nyai Denok, yang dipercaya jika ada orang sakit maka minta kesembuhan di sana dan ketika sembuh orang yang meminta kesembuhan tersebut akan menyembelih ayam besar dan menyembelihnya disana, tidak hanya manusia yang dimintakan kesembuhan, namun juga hewan ternak mereka yang sakit di bawa kesana.

\subsubsection{Foklor di Desa Sendang Mulyo}

Desa Sendangmulyo, Kecamatan Tembalang memiliki luas wilayah $358.57 \mathrm{~km}^{2}$, dengan atas wilayah di sebelah utara berbatasan dengan Kelurahan Kedungmundu, Plamongan, sebelah selatan Meteseh, sebelah barat Mangunharjo, sebelah timur Kali Babo, Kab. Demak. Dengan jumlah penduduk 37.506, terbagi menjadi $11.697 \mathrm{KK}$, laki-laki 18.834 jiwa dan perempuan 18.672 jiwa.. Mayoritas pekerjaan penduduknya sebagai buruh industri, kebanyakan lulusan SMA

Di Desa ini dulunya terdapat sendang yang airnya mengaliri sawah yang sangat luas, sehingga membuat orang-orang yang tinggal di daerah tersebut hidupnya kecukupan. 
Sehingga daerah itu dinamai dengan Sendhangmulyo yang berarti sendang dan mulyo yang berarti mata air yang membawa kemakmuran.

Saat ini sendang yang ada di Desa Sendangmulyo masih ada dan masyarakat setempat tidak berani untuk menutupnya.terdapat dua sendang, jarak antara kedua sendang cukup jauh. Mitosnya kedua sendang itu saling berkaitan dan melambangkan sendang wanita yang ada di dusun klipang letaknya di sebuah taman perumahan dan sendang laki-laki di dusun Dadapan di depan masjid. Sendang wanita masih biasanya didatangi oleh warga masyarakat sekitar yang akan membuat hajatan dengan menaruh sesajen di sekitar kolamnya.

\subsubsection{Foklor Desa Meteseh}

Desa Meteseh, Kecamatan Tembalang dahulu ikut Kec. Ungaran, pada tahun 1975 menjadi bagian dari Kec. Tembalang. Meteseh berasal dari kata teseh yang berarti masih. Konon ketika memanen padi, padi yang sudah di pangkas akan tumbuh lagi dan tidak ada habisnya, sehingga dinamai meteseh.

\subsection{Nilai Tradisi Lokal di Masyarakat Kecamatan tembalang}

Kecamatan Tembalang sebagai kecamatan yang masuk dalam Kota Semarang, memiliki tradisi yang khas wilayah pesisir panturaan. Dari hasil penelitian lima desa yang ada di Kec. Tembalang, rata-rata setiap desa memiliki tradisi, dan kesenian yang sama. Masyarakat pesisir juga sangat kuat dengan unsur keagamaanya, untuk itu banyak tradisi-tradisi yang bersangkutan dengan nilai keagamaan.Etos Kerja dari sifat yang dimiliki oleh masyarakat pesisir yang di dasari dengan sifat religiusitas inilah yang membawa pada sikap peduli terhadap tradisi keagamaan.

Tradisi merupakan suatu yang berkaitan dengan masa lalu dan masa sekarang.Tradisi merupakan hasil dari warisan turun temurun tiap generasi (Rahman, 2012: 440).

Eric Hobsbawm (1983) berpendapat: "Invented tradition is taken to mean a set of practices, normally governed by overtly or tacitly accepted rules and of a ritual or simbolic nature, which seek to inculcate certain values and norms of behaviour by repetition, which automatically implies continuity with the past" (Hobsbawm \& Ranger, 1983: 1-14).

Pada prinsipnya menurutnya bahwa penciptaan tradisi adalah suatu proses upaya yang berkenaan dengan penerimaan aturan tertulis maupun tidak tertulis yang bersifat ritual atau simbolik, berupa suatu usaha penanaman nilai-nilai atau norma-norma tertentu dalam perilaku dengan cara pengulangan, yang secara otomatis merupakan kesinambungan dengan masa lalunya. Handler dan Linnekin (1984) menambahkan bahwa tradisi harus dipahami sebagai suatu proses simbolisasi yang merujuk pada simbolisme masa lalu dan diinterpretasikan kembali. Hal ini dapat pula dikatakan sebagai suatu proses interpretasi, yaitu pemberian makna atau nilai terhadap kondisi masa sekarang, walaupun harus merujuk pada masa lalu. Habsbawm (1983) memberikan contoh pembangunan gedung parlemen di Inggris pada abad ke-19 dengan masih menggunakan gaya klasik Gotik yang dimodifikasi dengan konstruksi yang lebih modern.

Tradisi yang saat ini masih ada di setiap desa yang ada di Kec.Tembalang seperti, 1).Kenduri, merupakan tradisi selamatan 2). Tradisi bersih kubur biasanya dilakukan di bulan Rajab dengan menyembelih kambing dan dimakan bersama-sama di makam 3).Barian atau dalam arti lainnya yaitu Nyadran merupakan suatu tradisi yang biasanya di lakukan pada malam jumat kliwon.Setiap orang di wajibkan membawa makanan hasil laut.Dahulu Barian dilaksanakan di perempatan jalan dengan model bancaan/ makan bersama dalam satu wadah di pinggir jalan, namun karena seusai melakukan itu jalan menjadi kotor akhirnya acaranya sekarang diadakan di masjid atau mushola. 4). Tradisi Punggahan dan Pudunan yang biasanya 
di adakan di akhir bulan syaban (punggahan), akhir bulan ramadhan (pudunan) merupakan tradisi umat islam berziarah ke makan keluarga, 5). Tradisi Ziarah kubur, di tembalang terdapat sebuah makam $\mathrm{Ki}$ galanng sewu yang merupakan ponakan dari Pangeran Diponegoro, biasanya makam itu rutin diziarahi oleh para tokoh agama dan mahasiswa yang nyantri. 6). Tradisi sedekah bumi, 7). Tradisi Apitan atau sedekah desa yang biasanya dilakukan dengan pagelaran seni wayang.Tradisi- tradisi yang ada di Kec.Tembalang sangat berkaitan dengan kearifan lokal dan unsur pemaknaan simbolik dibalik tradisi yang dilakukan para pelakunya.

Kearifan lokal menurut Keraf (2005) harus bersifat komunal secara kepemilikan dan tidak individual. Dimana kearifan lokal mempunyai sifat keterbukaan dan dapat dipraktekan dalam kehidupan sepanjang usia komunitas yang ada. Kearifan lokal juga lebih bersifat aplikatif dan pragmatis dengan landasan filosofi yang dipahami bersama.Kearifan lokal menyangkut bagaimana berhubungan secara baik dengan semua isi alam.Kearifan lokal lebih bersifat holistic menyangkut kehidupan mikrokosmos dan makrokosmos. Kearifan lokal merupakan refleksi moralitas yang didasarkan pada prinsip tabu dan hanya dapat dipahami dalam kerangka tradisional. Kearifan lokal juga mempunyai sifat-sifat lokal dari refleksi karakteristik komunitas lokal (dalam Marfai, 2012: 35).Dalam telaah simbolik menurut Turner bahwa suatu tafsir terhadap simbol-simbol tidak akan lengkap dan mantap tanpa memperhatikan pandangan atau tafsir yang diberikan oleh pemilik atau pembuat simbol itu sendiri (dalam Sumintarsih, dkk., 2013:12).Semua bentuk tradisi keagamaan secara simbolik yang ada di Kec.Tembalang merupakan perwujudan dari ungkapan rasa syukur terhadap nikmat yang telah diberikan oleh Tuhan YME.

Ada juga Kearifan lokal dalam menjaga mitos-mitos yang terdapat di setiap desa yang ada di Kec.Tembalang. Desa Sendangmulyo merupakan desa yang namanya berasal dari sendang yang terdapat di daerah tersebut. Pengetahuan akan pentingnya kearifan lokal yang perlu di jaga membuat sendang yang menjadi asal muasal mitos cerita lisan yang berkembang di desa Sendangmulyo masih terjaga dan dirawat dengan baik. Mitos yang ada di desa tembalang tentang sumber mata air sampai saat ini pun masih ada sumbernya, hanya saja tidak sebanyak dahulu, dan sumer mata air tersebut sekarang menjadi kearifan lokal masyarakat Desa Tembalang.

Mitos sering dikaitkan dengan melegitimasikan agama atau kepercayaan, misalnya tentang cerita mitologi dewa-dewi atau cerita tentang roh-roh halus. Walaupun demikian di dunia politik, mitos juga sering untuk melegitimasikan ideologi atau kekuasaan. Baik dalam aspek agama atau politik, mitos berkaitan dengan kepercayaan tentang kebenaran agama, tradisi atau politik tertentu. Hal ini juga sesuai dengan pendapat Ahimsa-Putra (1995: 124) bahwa mitos sering merupakan sumber kebenaran atau alat untuk pembenaran. Sesuatu yang perlu dibenarkan melalui mitos ini dapat berupa ideologi, tradisi, kebudayaan, bahkan agama. Oleh karena itu membangun mitos dapat diartikan pula sebagai membangun kepercayaan tentang kebenaran, walaupun kebenaran yang dibangun sering bukan kebenaran yang rasional. Dalam suatu interaksi sosial, simbol-simbol yang berbentuk mitos ini memang harus disampaikan melalui pesan-pesan, baik secara langsung oleh pemilik simbol ataupun secara tidak langsung melalui media-media sosial, benda, bangunan dan sebagainya.

\subsection{Aspek Simbolik Seni Pertunjukan}

Seni pertunjukan adalah suatu tradisi produk kebudayaan yang ditujukan untuk hiburan. Masyarakat Kec. Tembalang mempunyai keanekaragaman seni pertunjukan diantaranya ialah wayang, ketoprak, kuda lumping atau jaran kepang, sanggar tari. Kesenian tersebut masih dilestarikan dan biasanya dilakukan bersamaan dengan acara tradisi lainnya. Seni pertunjukan biasa dipagelarkan sebagai pelengkap dan untuk hiburan. 
Aspek simbolik di dalam seni adalah sifat tradisionalnya yang turun temurun. Sesuai dengan sifat-sifat simbol yang arbitrary dan conventional, maka simbol-simbol di sini berfungsi sebagai identitas sosial dan perekat ikatan sosial, yang selanjutnya akan menciptakan etos kebersamaan sebagai suatu bentuk kearifan lokal.

Desa Bulusan sekelompok remaja yang menggerakan kesenian kuda lumping, mereka tergabung dalam kelompok yang bernama Turonggo Seto. Kelompok seni pertunjukan ini bahkan sudah diundang sampai ke luar kota. Desa Tembalang juga mempunyai seni pertunjukan yang diadakan secara rutin sebulan sekali bernama Sanggar Tari

\section{Simpulan}

Folklor merupakan bagian dari suatu produk budaya masyarakat. Folklor sangat penting untuk dipahami dalam setiap masyarakat karena hal ini sangat erat kaitanya dengan aspek simbolik dan identitas suatu masyarakat itu sendiri. Diantara sifat-sifat folklor ialah disebarkan secara lisan, tradisional, anonim, pralogis, milik bersama, polos dan lugu.Jenis folklor yang biasa berkembang di Kecamatan Tembalang diantaranya ialah cerita lisan, kebiasaan sosial masyarakat, dan seni pertunjukan.Pengetahuan tentang kearifan lokal sangat diperlukan dalam merawat suatu folklor dan tradisi di dalamnya.

Relasi folklor dengan etos kerja ialah tentang bagaimana folklor dapat menumbuhkan rasa keyakinan, semangat kebersamaan yang dapat membentuk suatu identitas yang ada di masyarakat sehingga terwujud juga dalam identitas individu setiap masyarakat.

\section{Daftar Pustaka}

Ahimsa-Putra, Heddy Shri. 2001, Strukturalisme Levi-Strauss: Mitos dan Karya Sastra, Yogyakarta: Galang Press.

Danandjaja, James. 1991. Folklor Indonesia, Jakarta: Pustaka Utama Grafiti, hal. 2.

Endraswara, Suwardi. 2009. Metode Penelitian Folklor. Yogyakarta: Medpress.

Harun, Muhammad, dkk. 2015. Revitalisasi Nilai Etos Kerja Dalam Hadih Maja Sebagai Bahan Ajar Pendidikan Karakter.Jounal of EST, Vol. 1 No. 3, FKIP Universitas Syiah Kuala.https://www.researchgate.net/publication/320047348_revitalisasi_nilai_etos_kerj a_dalam_hadih_maja_sebagai_bahan_ajar_pendidikan_karakter

Hayati, Naila. Tt. Pemilihan Metode Kuantitatif dan Metode Kualitatif. Jurnal Tarbiyag alawlad.Vol VI, Edisi 1, hlm.345-357. https://journal.tarbiyahiainib.ac.id/ index.php/awlad/article/viewFile/196/166.

Hobsbawm, Eric \& Ranger, Terence (ed). 1983. The Invention of Tradition, New York: Cambridge University Press.

Linnekin, Jocelyn, \& Handler, Richard. 1984. "Tradition, Genuine or Spurious", dalam Journal of American Folklore vol. 97. No. 385, by The American Folklore Society 0021-8715/84/3850273-1852.30/1, hal 273-290.

Marfai, Muh Aris. 2012. Pengantar Etika Lingkungan dan Kearifan Lokal. Yogyakarta: Gadjah mada university press, hlm 35 .

Rahman, M. Gazali. 2012. Tradisi Molonthalo di Gorontalo. Jurnal Al-Ulum, Vol. 2, No. 2 hlm. 440. https://media.neliti.com/media/publications/184347-ID-tradisi-molonthalo-digorontalo.pdf

Sumintarsih, dkk. 2013. Kearifan Lokal. Yogyakarta: Balai Pelestarian Nilai Budaya. hlm.12.

Sulaeman, M. Munandar. 1988.Ilmu Budaya Dasar: Suatu Pengantar, Bandung: Eresco, hal. 40.

Utami, Novi, dkk. tt. Etos Kerja Masyarakat yang Tercermin Dalam Legenda Pontianak. Pontianak: Jurnal FKIP UNTAN. 
Endogami: Jurnal Ilmiah Kajian Antropologi Vol. 2 No. 1 : Desember 2018 E-ISSN : 2599-1078

Vredenbregt, J. 1984. Metode dan Teknik Penelitian Masyarakat. Jakarta: PT. Gramedia, hal. 92. 